\title{
Development and Assessment of PharmaCheck: An Electronic Screening Tool for the Prevention of Twenty Major Adverse Drug Events
}

Christian Skalafouris ( $\square$ Christian.Skalafouris@hcuge.ch )

University Hospital of Geneva

Jean-Luc Reny

University Hospital of Geneva

Jérôme Stirnemann

University Hospital of Geneva

Olivier Grosgurin

University Hospital of Geneva

Francois Eggimann

University Hospital of Geneva

Damien Grauser

University Hospital of Geneva

Daniel Teixeira

University Hospital of Geneva

Megane Jermini

University Hospital of Geneva

Christel Bruggmann

University Hospital of Geneva

Pascal Bonnabry

University Hospital of Geneva

Bertrand Guignard

University Hospital of Geneva

\section{Research Article}

Keywords: clinical pharmacy, clinical decision support system (CDSS), rule-based system, clinical rules

Posted Date: August 24th, 2021

DOl: https://doi.org/10.21203/rs.3.rs-816129/v1 
License: (c) (i) This work is licensed under a Creative Commons Attribution 4.0 International License. Read Full License 


\section{Abstract}

Background: Adverse drug events (ADEs) can be prevented by deploying clinical decision support systems (CDSS) that directly assist physicians, via computerized order entry systems, and clinical pharmacists performing medication reviews as part of medical rounds. However, physicians using CDSS are known to be exposed to the alert-fatigue phenomenon. Our study aimed to assess the performance of PharmaCheck-a CDSS to help clinical pharmacists detect high-risk situations with the potential to lead to ADEs-and its impact on clinical pharmacists' activities.

Methods: Twenty clinical rules, divided into four risk classes, were set for the daily screening of high-risk situations in the electronic health records of patients admitted to our General Internal Medicine Department. Alerts to clinical pharmacists encouraged them to telephone prescribers and suggest any necessary treatment adjustments. PharmaCheck's performance was assessed using the intervention's positive predictive value (PPV), which characterizes the proportion of interventions for each alert triggered. PharmaCheck's impact was assessed by considering clinical pharmacists as a filter for ruling out futile alerts and by comparing the final clinical PPV with a pharmacist (the proportion of interventions that led to a change in the medical regimen) to the final clinical PPV without a pharmacist.

Results: Over 132 days, 447 alerts were triggered for 383 patients, leading to 90 interventions (overall intervention PPV $=20.1 \%$ ). By risk class, intervention PPVs made up $26.9 \%(n=65 / 242)$ of abnormal laboratory value alerts, $3.1 \%(4 / 127)$ of alerts for contraindicated medications or medications to be used with caution, $28.2 \%$ (20/71) of drug-drug interaction alerts, and $14.3 \%(1 / 7)$ of inadequate mode of administration alerts. Clinical PPVs reached $71.0 \%$ (64/90) when pharmacists filtered alerts and $14 \%$ $(64 / 242)$ if they were not doing it.

Conclusion: PharmaCheck enabled clinical pharmacists to improve their traditional processes and broaden their coverage by focusing on 20 high-risk situations. Alert management by pharmacists seemed to be a more effective way of preventing risky situations and alert fatigue than a model addressing alerts to physicians exclusively. Some fine-tuning could enhance PharmaCheck's performance by considering the information quality of triggers, the variability of clinical settings, and the fact that some prescription processes are already highly secured.

\section{Background}

Adverse drug events (ADEs) can occur during a patient's drug therapy and can result from either appropriate, inappropriate, or suboptimal care. (1) ADEs are a well-known source of hospital morbidity and mortality, and they may account for about $19 \%$ of all the injuries to hospitalized patients, in addition to their economic burden (estimated direct costs in hospital settings vary from EUR 943 to EUR 7,192 per patient). (2-4) Nevertheless, medication errors can occur at any stage in the treatment process, from prescription to administration, and lead to ADEs. (5) Thus, a significant proportion of ADEs could be prevented, particularly using strategies to improve prescription safety. $(6,7)$ 
Combining a computerized physician order entry (CPOE) system with a clinical decision support system (CDSS) is an effective way of ensuring drug prescription safety. (8) CPOE includes three features: direct entry of drug prescriptions by the physician, use of a digital interface, and standardized, structured information entry. (9) These characteristics make it possible to superimpose CDSS onto a CPOE system to assist prescribing physicians. CDSS link information from patients' electronic health records (EHRs, e.g., computerized drug prescriptions) to knowledge databases and deliver information to the provider to improve the quality of medication prescriptions. (10) When coupled with CPOE, a CDSS can produce reminders or alerts to prevent any act of commission or omission that might lead to ADEs. Although this approach has shown some effectiveness in leading to changes in drug treatments (with an estimated requirement of 331 alerts to prevent $1 \mathrm{ADE}$ ), it does have some limitations, and the override rate for the information provided has varied between $60 \%$ and $90 \%$ despite significant relevance. $(11-13)$ Several factors may explain a poor adherence rate, especially the cognitive overload (particularly with alerts that give little information or occur in complex work situations) that leads to the alert-fatigue phenomenon. (14) Thus, using CDSS helps reduce the incidence of ADEs but is an insufficient way given these limitations.

Clinical pharmacy services contribute to reducing medication errors and ADEs through a variety of interventions (e.g., medication reconciliation at admission/discharge, medication review and participation in medical rounds, drug-specific pharmacy services). $(15,16)$ However, in many European countries, clinical pharmacy services are still somewhat scarce. A 2010 survey indicated that only about $40 \%$ of hospital pharmacies offered clinical pharmacy services to their colleagues, with great disparities between countries (from 3.6\% to 79.2\%). (17) Such disparities also exist in Switzerland. A national survey showed that only $15.0 \%$ of hospital pharmacists were assigned to clinical pharmacy duties, with great regional disparities (from $9.9 \%$ to $27.4 \%$ full-time equivalent pharmacists allocated to clinical pharmacy activities). Switzerland has been ranked twentieth out of thirty European countries in the provision of clinical pharmacy services. These values reflect a lack of human resources available to provide quality pharmaceutical care to an aging, polymedicated population with chronic diseases. $(17,18)$ In our hospital, pharmaceutical resources are insufficient to attend to every patient requiring a medication review. A previous study indicated that one clinical pharmacist could perform medication reviews for 15 patients per day. (19) Our present resources would only allow us to cover a small portion of all inpatients.

As mentioned above, computerization is supposed to help meet the two major challenges facing hospitals: providing better care and lowering costs. Furthermore, we hypothesized that the performance of CDSS in preventing ADEs could be improved if they were managed by clinical pharmacists. It might also increase pharmacists' scope for action by making it possible for them to identify greater numbers of high-risk situations that might lead to an ADE. Our study aimed to assess the performance of a screening tool for the detection of high-risk situations with the potential to lead to an ADE as well as the tool's impact on the activity of clinical pharmacists.

\section{Methods}




\section{Setting}

Integrated computerized patient records have been part of the 2,000-bed Geneva University Hospitals' information system since the early 2000s, providing administrative and demographic data, structured hospitalization reports (e.g., forms, discharge letters, progress notes, radiology reports, nursing reports), laboratory values, and CPOE. The CPOE is supported by a CDSS for suggesting in-label and default values for drugs, dosages, and routes of administration. The CDSS also performs several checking procedures (e.g., for the presence of a drug allergy, medication duplication, drug-drug interactions, and overdosage). Most of the alerts it generates are displayed during the prescription process and must be acknowledged by the physician to ensure the medical order to be validated.

\section{Selection of clinical rules}

A two-stage process was used to select the clinical rules for screening high-risk situations that might lead to major adverse drug events. Firstly, situations described as 'critical' in international guidelines-or treated as such in an equivalent screening tool developed by the "Hôpital du Valais" (another Swiss hospital) to target highly critical situations-had to be assessed. (20-22) Those assessed critical situations had to match the profile for patients admitted to our General Internal Medicine Department (i.e., polymorbid and polymedicated adults). Secondly, a set of clinical rules that could be transposed into our CDSS and based on triggers identifiable from electronic queries were selected by two clinical pharmacists.

The 20 clinical rules selected after this process were divided into four risk categories: drugs prescribed when the patient shows abnormal laboratory values (12 clinical rules); contraindicated medications or medications to be used with caution depending on the clinical context (3 clinical rules); prescriptions involving a drug-drug interaction (DDI, 2 clinical rules); and medication prescribed with an inadequate mode of administration (3 clinical rules). Drugs prescribed with abnormal laboratory values were subdivided into three sub-categories: drugs prescribed in the presence of renal failure; drugs prescribed in combination with a supra-therapeutic serum level; drugs prescribed in combination with an abnormal laboratory value, indicating a risk of overdosage or adverse effect. Clinical rules, risk categories, and subcategories are listed in Table 1.

\section{PharmaCheck's development}

PharmaCheck is the result of a collaboration between our hospital's pharmacy and information systems departments. We decided to develop a CDSS for clinical pharmacists in-house because patients' EHRs are stored in a document-based database (DPI-DATA) that is consultable using MongoDB aggregation operations. Aggregation operations group values from multiple sources together and can perform a variety of operations on those grouped data to return a single result. (23) An 'aggregation pipeline' approach was used so that documents enter a multi-stage pipeline that transforms them into an 
aggregated result. Aggregation operations were built and tested using Studio 3T software for MongoDB (version 2019.5.1) and involved structured data (drug prescriptions, laboratory values, vital signs, demographics) and unstructured data (medical problems). (24) PharmaCheck was constructed as a clinical, rules-based system. Accordingly, knowledge is specified via facts and IF-THEN rules, and modus ponens was used as the underlying inference method for deriving new conclusions from existing knowledge. (25) An illustration of an aggregation pipeline is represented in Figure 1. For each high-risk situation assessed, PharmaCheck renders a table presenting the patient's characteristics and all the trigger values. According to the situation assessed, other informative values that might ease clinical decision-making are displayed (e.g., previous laboratory values, medication history). The triggering elements and informative values associated with each clinical rule are presented in Table 1.

Table 1

Description of the twenty clinical rules 


\begin{tabular}{|c|c|c|c|}
\hline Risk category & $\begin{array}{l}\text { Description of the } \\
\text { clinical rule }\end{array}$ & Triggers & $\begin{array}{l}\text { Other informative } \\
\text { values displayed }\end{array}$ \\
\hline \multirow{18}{*}{$\begin{array}{l}\text { Drug } \\
\text { prescription } \\
\text { with an } \\
\text { abnormal lab } \\
\text { value }\end{array}$} & \multirow{2}{*}{$\begin{array}{l}\text { Prescription of a } \\
\text { DOAC in the } \\
\text { presence of an acute } \\
\text { renal failure }^{1}\end{array}$} & $\begin{array}{l}\text { Active prescription: apixaban or } \\
\text { dabigatran or edoxaban or } \\
\text { rivaroxaban }\end{array}$ & \multirow{2}{*}{$\begin{array}{l}\text { Prescribed strong } \\
\text { inducers/inhibitors } \\
\text { of P-gp/CYP3A4; } \\
\text { Previous } \\
\text { creatinine values }\end{array}$} \\
\hline & & $\begin{array}{l}\text { Laboratory value: CICG } \leq 30 \\
\mathrm{~mL} / \text { min (computed with lowest } \\
\text { body weight (between measured } \\
\text { and ideal body weight)) }\end{array}$ & \\
\hline & \multirow{2}{*}{$\begin{array}{l}\text { Prescription of } \\
\text { colchicine in the } \\
\text { presence of an acute } \\
\text { renal failure }^{1}\end{array}$} & Active prescription: colchicine & \multirow{2}{*}{$\begin{array}{l}\text { Prescribed strong } \\
\text { inducers/inhibitors } \\
\text { of P-gp/CYP3A4; } \\
\text { History of } \\
\text { creatinine values }\end{array}$} \\
\hline & & $\begin{array}{l}\text { Laboratory value: CICG } \leq 30 \\
\mathrm{~mL} / \text { min (computed with lowest } \\
\text { body weight (between measured } \\
\text { and ideal body weight)) }\end{array}$ & \\
\hline & \multirow{2}{*}{$\begin{array}{l}\text { Prescription of } \\
\text { morphine in the } \\
\text { presence of an acute } \\
\text { renal failure }^{1}\end{array}$} & Active prescription: morphine & \multirow{2}{*}{$\begin{array}{l}\text { Previous } \\
\text { creatinine values }\end{array}$} \\
\hline & & $\begin{array}{l}\text { Laboratory value: CICG } \leq 15 \\
\mathrm{~mL} / \text { min (computed with lowest } \\
\text { body weight (between measured } \\
\text { and ideal body weight)) }\end{array}$ & \\
\hline & \multirow{2}{*}{$\begin{array}{l}\text { Prescription of } \\
\text { metformin in the } \\
\text { presence of an acute } \\
\text { renal failure }^{1}\end{array}$} & Active prescription: metformin & \multirow{2}{*}{$\begin{array}{l}\text { Previous } \\
\text { creatinine values }\end{array}$} \\
\hline & & $\begin{array}{l}\text { Laboratory value: CICG } \leq 30 \\
\mathrm{~mL} / \mathrm{min} \text { (computed with lowest } \\
\text { body weight (between measured } \\
\text { and ideal body weight)) }\end{array}$ & \\
\hline & \multirow{2}{*}{$\begin{array}{l}\text { Prescription of } \\
\text { metformin in the } \\
\text { presence of } \\
\text { hyperlactatemia }^{2}\end{array}$} & Active prescription: metformin & \multirow{2}{*}{$\begin{array}{l}\text { Previous lactate } \\
\text { values }\end{array}$} \\
\hline & & $\begin{array}{l}\text { Laboratory value: lactatemia } \geq 5.0 \\
\mathrm{mmol} / \mathrm{L}\end{array}$ & \\
\hline & \multirow{3}{*}{$\begin{array}{l}\text { Prescription of } \\
\text { heparin in the } \\
\text { presence of a } \\
\text { thrombopenia }{ }^{2}\end{array}$} & Active prescription: LMWH, UFH & \multirow{2}{*}{$\begin{array}{l}\text { Previous LMWH } \\
\text { and/or UFH } \\
\text { prescriptions }\end{array}$} \\
\hline & & $\begin{array}{l}\text { Laboratory value: platelets } \leq 50 \\
\mathrm{G} / \mathrm{L}\end{array}$ & \\
\hline & & & $\begin{array}{l}\text { Previous platelet } \\
\text { count }\end{array}$ \\
\hline & \multirow{2}{*}{$\begin{array}{l}\text { Prescription of } \\
\text { digoxin in the } \\
\text { presence of } \\
\text { dyskaliemia }^{2}\end{array}$} & Active prescription: digoxine & \multirow{2}{*}{$\begin{array}{l}\text { Previous digoxin } \\
\text { prescriptions } \\
\text { Previous } \\
\text { potassium values }\end{array}$} \\
\hline & & $\begin{array}{l}\text { Laboratory value: kaliemia } \leq 3.5 \\
\mathrm{mM} \text { or kaliemia } \geq 5.5 \mathrm{mM}\end{array}$ & \\
\hline & \multirow{2}{*}{$\begin{array}{l}\text { Prescription of } \\
\text { digoxin in the } \\
\text { presence of high rate } \\
\text { of digoxinemia }^{2}\end{array}$} & Active prescription: digoxine & $\begin{array}{l}\text { Previous digoxin } \\
\text { prescriptions }\end{array}$ \\
\hline & & $\begin{array}{l}\text { Laboratory value: digoxinemia } \geq 3 \\
\mathrm{nM}\end{array}$ & $\begin{array}{l}\text { Previous digoxin } \\
\text { values }\end{array}$ \\
\hline & $\begin{array}{l}\text { Prescription of a } \\
\text { blood-glucose- }\end{array}$ & $\begin{array}{l}\text { Active prescription: blood-glucose- } \\
\text { lowering drug (ATC A10B) }+\end{array}$ & $\begin{array}{l}\text { Previous glucose } \\
\text { values }\end{array}$ \\
\hline
\end{tabular}


lowering drug in the presence of

hypoglycemia ${ }^{2}$

Prescription of VKA in the presence of a supra-therapeutic INR $^{3}$

insulins (exclusion of PRN prescriptions)

Laboratory value: glycemia $\leq 4 \mathrm{mM}$

Active prescription: acenocoumarol, fluindione, warfarin, phenprocoumon

Previous doses of VKA; Previous INR values

Laboratory value: INR $\geq 4$

Prescription of vancomycin in the presence of high rate of vancomycinemia ${ }^{3}$

Active prescription: vancomycin

Laboratory value: vancomycinemia $\geq 25 \mathrm{mg} / \mathrm{L}$

Prescription of gentamicin with supratherapeutic gentamycine rate

Prescription of tobramycin with supratherapeutic tobramycin rate

Prescription of amikacin with supratherapeutic amikacin rate ${ }^{3}$

Medication contraindicated or to be used with caution
Anticholinergic drugs and some comorbidities (e.g., dementia, urinary retention, constipation) $(55,56)$
Active prescription: gentamicin or tobramycin or amikacin

Laboratory value: gentamicinemia $\geq 1 \mathrm{mg} / \mathrm{L}$; tobramycinemia $\geq 1$ $\mathrm{mg} / \mathrm{L}$; amikacinemia $\geq 5 \mathrm{mg} / \mathrm{L}$
Previous gentamicin, tobramycin, amikacin levels
Previous vancomycin levels
Active prescription: acepromazine and/or aminoalkyl ethers and/or and/or antazoline and/or anticholinergic agents and/or azatadine and/or bamipine and/or buclizine and/or buclizine, combinations and/or carbamazepine and/or chlorcyclizine and/or chlorpromazine and/or cinnarizine + combinations and/or cinnarizine and/or clozapine and/or clozapine and/or cyamemazine and/or cyclizine and/or cyclizine, combinations and/or cyproheptadine and/or deptropine and/or dimetindene and/or disopyramide and/or drugs for functional gastrointestinal disorders and/or drugs for urinary frequency and incontinence and/or fluphenazine and/or hydroxyzine + combinations and/or hydroxyzine and/or hyoscyamine and/or levomepromazine and/or loxapine and/or mebhydrolin and/or meclozine and/or meclozine, combinations and/or nefopam
Medication history (extracted from admission note) 
and/or non-selective monoamine reuptake inhibitors and/or

oxatomide and/or oxcarbazepine and/or paroxetine and/or pethidine and/or phenindamine and/or phenothiazine derivatives and/or pimethixene and/or pimozide and/or piritramide and/or pizotifen and/or propantheline and/or pyrrobutamine and/or pyrrobutamine, combinations and/or quetiapine and/or scopolamine (hyoscine) and/or scopolamine and/or substituted alkylamines and/or substituted ethylene diamines and/or synthetic anticholinergic agents in combination with analgesics and/or synthetic anticholinergics, esters with tertiary amino group and/or synthetic anticholinergics, quaternary ammonium compounds and/or synthetic antispasmodics, amides with tertiary amines and/or thenalidine and/or thenalidine, combinations and/or thioridazine and/or thiothixene and/or tizanidine

Active problem (indicated in the admission note): dementia, acute confusional state, confusion, urinary globe, prostatism, urine retention, acute angle-closure glaucoma, cardiac conduction disorder

Drugs potentially lowering seizure threshold and epilepsy or history of seizure (56)
Active prescription: anticholinergic agents and/or antihistamines for systemic use and/or azithromycin and/or beta-lactam antibacterials, penicillins and/or bupropion and/or busulfan and/or calcineurin inhibitors and/or carmustine and/or chlorambucil and/or chlorpromazine and/or clonidine and/or clozapine and/or cyamemazine and/or disopyramide and/or domperidone and/or drugs for urinary frequency and incontinence and/or enflurane and/or ephedrine and/or ephedrine and/or flumazenil and/or foscarnet and/or ganciclovir and/or h2receptor antagonists and/or haloperidol and/or hydroxyzine and/or ketamine and/or ketoconazole and/or levomepromazine and/or lidocaine and/or lithium and/or loxapine
Medication history (extracted from admission note) 
and/or mefloquine and/or

methotrexate and/or

methylphenidate and/or

metronidazole and/or midecamycin

and/or muscle relaxants, centrally

acting agents and/or nefopam

and/or non-selective monoamine

reuptake inhibitors and/or other

beta-lactam antibacterials and/or

oxetorone and/or oxybutynin

and/or pentazocine and/or

pethidine and/or phenothiazines

with aliphatic side-chain and/or

phenothiazines with piperazine

structure and/or

phenylpropanolamine and/or

pimozide and/or piritramide and/or

pizotifen and/or propantheline

and/or pyrimethamine and/or

quinolone antibacterials and/or

scopolamine and/or selective

serotonin reuptake inhibitors and/or

synthetic anticholinergic agents in

combination with analgesics

and/or terbutaline and/or

theophylline and/or tramadol

and/or vincristine and/or

Active problem (indicated in the

admission note): epilepsy

NSAID and some comorbidities (e.g., renal failure, heart failure) (56)
Active prescription: NSAID (ATC $=$ $\mathrm{M} 01 \mathrm{~A}$ ) and/or metamizole and metamizole, combinations excl. psycholeptics and/or metamizole, combinations with psycholeptics

Active problem (indicated in the admission note): chronic renal failure and/or heart failure and/or myocardial infarction and/or gastric ulcer and/or duodenal ulcer and/or gastroduodenal ulcer
DDI

Co-prescription of 2 anticoagulants
Active prescription: acenocoumarol and/or apixaban and/or dabigatran and/or fluindione and/or LMWH and/or prophencoumon and/or rivaroxaban and/or UFH and/or warfarin (VKA and LMWH or UFH excluded)

Co-prescription of 2 serotoninergic drugs (57)
At least two of the following active prescriptions: amitriptyline and/or bromocriptine and/or bupropion and/or buspirone and/or cabergoline and/or carbamazepine and/or citalopram and/or clomipramine and/or clozapine and/or dextromethorphane and/or
Medication history (extracted from admission note) 


\begin{tabular}{|c|c|c|}
\hline & & $\begin{array}{l}\text { dihydroergotamine and/or } \\
\text { dosulepine and/or doxepine and/or } \\
\text { eletriptan and/or ergotamine } \\
\text { and/or escitalopram and/or } \\
\text { fentanyl and/or fluoxetine and/or } \\
\text { fluvoxamine and/or haloperidol } \\
\text { and/or imipramine and/or } \\
\text { isoniazide and/or lamotrigine } \\
\text { and/or linezolide and/or lithium } \\
\text { and/or maprotiline and/or } \\
\text { methadone and/or metoclopramide } \\
\text { and/or mianserine and/or } \\
\text { mirtazapine and/or moclobemide } \\
\text { and/or naratriptan and/or } \\
\text { nortriptyline and/or olanzapine } \\
\text { and/or ondansetron and/or } \\
\text { oxycodone and/or paroxetine } \\
\text { and/or pergolide and/or pethidine } \\
\text { and/or quetiapine and/or } \\
\text { risperidone and/or rizatriptan } \\
\text { and/or selegiline and/or sertraline } \\
\text { and/or sibutramine and/or } \\
\text { sumatriptan and/or tramadol } \\
\text { and/or trazodone and/or } \\
\text { trimipramine and/or valproate } \\
\text { and/or venlafaxine and/or } \\
\text { zolmitriptan }\end{array}$ \\
\hline \multirow[t]{3}{*}{$\begin{array}{l}\text { Inadequate } \\
\text { mode of } \\
\text { administration } \\
\text { mode }\end{array}$} & $\begin{array}{l}\text { Scheduling } \\
\text { methotrexate doses } \\
\text { less than } 7 \text { days } \\
\text { apart }\end{array}$ & $\begin{array}{l}\text { Nursing scheduling of } 2 \text { MTX doses } \\
\text { in } a \leq 7 \text { days interval }\end{array}$ \\
\hline & $\begin{array}{l}\text { Prescription of } \\
\text { intravenous } \\
\text { potassium chloride } \\
\text { at too high a flow } \\
\text { rate }\end{array}$ & $\begin{array}{l}\text { Active prescription: parenteral } \\
\text { intravenous chloride flow rate }>10 \\
\mathrm{mmol} / \text { hour }\end{array}$ \\
\hline & $\begin{array}{l}\text { Prescription of } \\
\text { intravenous } \\
\text { potassium chloride } \\
\text { at too high a } \\
\text { concentration }\end{array}$ & $\begin{array}{l}\text { Active prescription: parenteral } \\
\text { intermittent intravenous chloride at } \\
\text { a concentration }>0.08 \mathrm{mmol} / \mathrm{mL} ; \\
\text { parenteral continuous intravenous } \\
\text { chloride at a concentration }>1.00 \\
\mathrm{mmol} / \mathrm{mL}\end{array}$ \\
\hline
\end{tabular}

Table 1: Each of the twenty clinical rules is classified according to four risk categories (drug prescription with an abnormal laboratory value; medication contraindicated or to be used with caution regarding clinical context; drug-drug interaction; inadequate mode of administration). Drug prescriptions with abnormal laboratory values are subdivided into three sub-categories (1: drug prescription in the presence of renal failure; 2: drug prescription combined with a supra-therapeutic serum level; 3 : drug prescription combined with an abnormal laboratory value indicating an overdosage or a risk of an adverse effect). 
Trigger factors are described for each clinical rule (prescribed drug, mode of drug administration, laboratory value, patient problem), as are all the displayed elements extracted from the computerized patient record and intended to facilitate decision-making.

List of abbreviations: DOAC - direct oral anticoagulant; VKA - vitamin K antagonist; NSAID - nonsteroidal anti-inflammatory drug; CICG - estimated creatinine clearance using the Cockcroft-Gault formula; LMWH - low molecular weight heparin; UFH - unfractionated heparin; ATC - anatomical therapeutic chemical; PRN - as needed; INR - international normalized ratio; MTX - methotrexate; P-gp permeability glycoprotein; CYP3A4 - Cytochrome P450 3A4.

\section{Study design}

PharmaCheck was developed over nine months and evaluated during a seven-month prospective observational study (February to August 2020) including all the patients admitted to a 200-bed general internal medicine department.

Electronic queries were run twice every working day to identify patients exposed to high-risk situations. Each alert was assessed for clinical relevance by a clinical pharmacist to decide whether a suggestion for therapeutic adjustment or additional monitoring should be sent to the prescriber (i.e., via a telephone call or during medical rounds). Decisional algorithms were constructed for the 20 situations to standardize pharmacists' analyses and intervention each time an alert was triggered (Figure 2). A pharmaceutical intervention was considered to have been accepted if it led to a change in patient management within 24 hours (e.g., modification of the drug prescription, additional monitoring).

We measured the distribution for each alert and a repetitive alert (the same alert occurring during several rounds of check using PharmaCheck) was only counted once if the pharmacist had already dealt with it. An electronic tracking file made it possible to document pharmacists' judgment and decisions (assessment of the situation, decision to intervene or to follow-up the situation) when they analyzed the alert and transmitted information to the rest of the pharmaceutical team in a targeted way.

PharmaCheck's ability to detect high-risk situations was assessed by measuring the clinical pharmacy intervention's positive predictive value (PPV) for each alert (i.e., the proportion of alerts that led to an intervention). The clinical pharmacist's ability to act as a filter, ruling out futile alerts, was assessed by comparing the final clinical PPV with pharmacists' interventions (i.e., the ratio of accepted therapeutic adjustments and/or additional monitoring to the number of interventions) to the final clinical PPV without pharmacists (i.e., the ratio of accepted therapeutic adjustments and/or additional monitoring to the total number of alerts). We also assessed the reasons why prescribers did not accept pharmaceutical suggestions. 


\section{Statistical analysis}

Results were expressed as medians (with their interquartile ranges and minimum-maximum values), means, and standard deviations (SDs). Non-normally distributed quantitative data were analyzed using non-parametric tests. Differences in the number of pharmaceutical interventions between groups were assessed using the non-parametric Mann-Whitney $U$ test. Univariate logistic regressions were calculated to identify variables with a strong effect on the probability of a pharmaceutical intervention and its acceptance (binary outcomes). The variables tested were patient age, number of treatments, and hospital length of stay. A $P$-value less than 0.05 was considered statistically significant. Data analysis was conducted using R software (version 3.6.3).

\section{Ethical consideration}

This quality-improvement study was set up as standard practice not falling within the scope of the Swiss law on research on human beings and the waiver of informed consent was reviewed and approved by the Ethics Committee of the Canton of Geneva, Switzerland. All experiments were performed in accordance with relevant guidelines and regulations. Clinical pharmacist's interventions were exclusively dedicated to physicians who finally decided on a prescription change. All patients admitted to the internal medicine department under cover of clinical pharmacy services were eligible as no exclusion criteria was defined. Patients did not provide informed consent as this service was implemented as standard of care.

\section{Results}

PharmaCheck was used to screen 5,466 patients' EHRs over 132 days. A total of 447 alerts were triggered for 383 patients ( $7.0 \%$ of the patients admitted during the study period). Each day, an average of $3.4 \pm 2.0$ new alerts were triggered. Patient characteristics and their distribution according to the presence of a pharmaceutical intervention are presented in Table 2; the distribution of alerts by risk category is presented in Table 3.

\section{Table 2}

Patient characteristics and their distribution according to the presence of a pharmaceutical intervention 


\begin{tabular}{|c|c|c|c|c|c|}
\hline \multirow{3}{*}{$\begin{array}{l}\text { Patients } \\
\text { characteristics } \\
\mathrm{n}=386 \text {; sex ratio } \\
(0.96)\end{array}$} & \multirow{2}{*}{\multicolumn{3}{|c|}{$\begin{array}{l}\text { Mean } \pm \text { SD } \\
\text { Median [IQR; min-max] }\end{array}$}} & \multirow[t]{3}{*}{$p$-value } & \multirow{3}{*}{$\begin{array}{l}\text { Odd ratio } \\
{[95 \mathrm{Cl}]}\end{array}$} \\
\hline & & & & & \\
\hline & Total & No intervention & Intervention & & \\
\hline \multirow[t]{2}{*}{ Age } & $70.7 \pm 15.6$ & $69.5 \pm 15.9$ & $75.6 \pm 134$ & \multirow[t]{2}{*}{$<0.001$} & 1.03 \\
\hline & $74[21 ; 17-97]$ & $73[24 ; 17-96]$ & $77[12 ; 19-97]$ & & {$[1.01 ; 1.05]$} \\
\hline \multirow{2}{*}{$\begin{array}{l}\text { Number of } \\
\text { treatments }\end{array}$} & $13.8 \pm 6.4$ & $13.8 \pm 6.4$ & $13.7 \pm 6.0$ & \multirow[t]{2}{*}{0.9} & 1.0 \\
\hline & $13[7 ; 1-40]$ & $13[7 ; 1-40]$ & $13[9 ; 3-30]$ & & {$[0.96 ; 1.03]$} \\
\hline \multirow[t]{2}{*}{ Length of stay } & $8.1 \pm 8.5$ & $8.2 \pm 8.5$ & $7.8 \pm 8.5$ & \multirow[t]{2}{*}{0.63} & 1.0 \\
\hline & $\begin{array}{l}5.9[9.5 ; 0.0- \\
84.0]\end{array}$ & $\begin{array}{l}5.64[9 ; 0.0- \\
84.0]\end{array}$ & $\begin{array}{l}6.4[8.5 ; 0.0- \\
27.8]\end{array}$ & & {$[0.96 ; 1.02]$} \\
\hline
\end{tabular}

Alert analyses led to 90 interventions for therapeutic adjustments or additional monitoring (intervention PPV $=20.1 \%$ ), of which 63 were accepted by prescribers (final clinical PPV with pharmacist $=71.0 \%$, final clinical PPV without pharmacist $=14.0 \%$ ). Patient age was the only variable to affect the probability of a pharmaceutical intervention, and none of the variables tested (age, number of treatments, length of stay) influenced the probability of a pharmaceutical intervention being accepted (data not shown). Prescribers decided not to follow 27 suggestions for therapeutic adjustments or additional monitoring, mainly because they assessed there was a positive benefit-risk ratio $(85.2 \%, n=23$ cases), but also for unknown reasons $(11.1 \%, n=3)$, and because the patient had already been discharged at the time of the intervention $(3.7 \%, n=1)$.

\section{Discussion}

We developed a screening tool to detect several high-risk situations with the potential to lead to a major ADE. Once detected, an alert was sent to clinical pharmacists, not directly to prescribers. Our main finding was that PharmaCheck was effective at detecting high-risk situations, with 447 situations identified during the study period. These alerts were considered relevant in 90 cases, with a suggested intervention addressed to the physician (intervention PPV $=20.1 \%$ ). The final clinical PPV including the pharmacist's intervention was $71 \%$-five times higher than if the pharmacist had not ruled out the non-clinically relevant alerts (final clinical PPV without a pharmacist $=14 \%$ ).

\section{PharmaCheck performance in the detection of high-risk situations}




\section{Patient characteristics associated with pharmacists' interventions}

In the present study, decisions to intervene appeared to be moderately positively correlated with patient age (the likelihood of pharmaceutical intervention increased with age). There was clear evidence that older patients were proportionately more polymorbid and polymedicated than younger patients, which exposed them to an increased risk of ADEs and, therefore, to triggering alerts and interventions. In addition, elderly patients' intrinsic characteristics may help explain this greater likelihood of intervention: pharmacokinetic and pharmacodynamic properties are age-related, and this population is exposed to more adverse events (e.g., reduced renal elimination, greater susceptibility to anticholinergic effects) that readily prompt pharmacists to intervene. (26-28)

\section{Intervention PPV associated with PharmaCheck}

The present study assumed that the intervention PPV reflected the specificity of a CDSS integrated into a CPOE and, thus, PharmaCheck's performance. Ninety of the 447 alerts led to a pharmaceutical intervention (intervention PPV $=20.1 \%$ ). According to a systematic review that assessed the reported PPV (ratio of relevant drug alerts to the total number of alerts), this indicator varied considerably, from $5.8 \%$ to $83 \%$, with the majority of results falling between $20 \%$ and $40 \%$. (29) It should be noted that few studies have analyzed the impact of advanced CDSS dedicated to clinical pharmacists for the prevention of selected, specific, high-risk situations. In such settings, intervention PPVs varied from $8 \%$ to $51 \%$. (3033) Although published studies have not systematically described reasons for non-intervention, different elements help to explain disparities in these results: logistical limitations (not enough resources to process every alert); technical limitations (low specificity linked to absent or insufficiently structured data in the EHRs); limitations associated with workflows (repetitive alerts that have already been analyzed, risk situations that physicians have already considered). (30-33) Our study identified three factors that may explain the disparities between the intervention PPVs for the different clinical rules. First, the nature and informative quality of the trigger elements (defined as any set of data in the EHR enabling the appropriate assessment of a clinical situation) affected alert relevance. Second, the clinical context and the physician's awareness of the risk situation enabled a better assessment of the need for an intervention. Third, additional redundant electronic safeguards (targeting known risk situations already and partially made safe by a CDSS) also influenced pharmaceutical interventions.

\section{Nature and information quality of trigger elements integrated into the CDSS}

As already noted, most of the clinical rules (12/20) concerned the 'drug prescription with abnormal laboratory values' risk category, accounting for more than half of the alerts (54.1\%) and with an intervention PPV of $26.9 \%$. Although, compared to alerts concerning other clinical rules, alerts concerning 
drug-laboratory interactions seemed to be the most relevant (reported intervention PPV up to 83\%). (29) It should be noted that in our study, their relevance depended on the sub-category of risk and its associated triggers. We observed the highest intervention PPV (33.9\%) in the 'drugs prescribed in the presence of renal failure' category, as these alerts are based on the prescription of a drug (direct oral anticoagulant, metformin, colchicine, and morphine) and an estimated level of renal function. To go one step further with these alerts, PharmaCheck was set to display several renal function values: estimated glomerular filtration rate (eGFR) based on the Chronic Kidney Disease Epidemiology Collaboration (CKDEPI) equation and estimated creatinine clearance using the Cockcroft-Gault (CG) equation, calculated using actual and ideal body weight but selecting the lowest one. $(34,35)$ Thus, most of the alerts were triggered by the CG with ideal body-weight clearance, whereas our EHRs calculated and displayed eGFR based on the CKD-EPI formula. Automatically providing and comparing these renal function estimates added value; otherwise, a time-consuming manual calculation would have been required.

In contrast, the second most frequent alert category was 'contraindicated medications or medications to be used with caution' (28.4\% of alerts), but it was associated with the lowest intervention PPV (3.1\%), which may translate into a low specificity clinical rule (since a low number of alerts was considered relevant to trigger an intervention with the physician). The development of clinical rules involving patient problems is challenging as these trigger elements are not commonly structured in an unequivocal way (e.g., using ICD-10 terminology and/or SNOMED CT). (36) Several studies have shown that the reliability of free-text searches through EHRs to characterize patients' problems is uncertain, with a sensitivity varying from $1 \%$ to $46 \%$. (37) The inaccuracy of free-text searching is underpinned by the lack of specificity in the problems described in the EHR on the one hand (problems mentioned with little or no diagnostic support may increase false-positives) and lack of sensitivity on the other (choosing a set of non-exhaustive trigger words for problem characterization may increase the false-negative rate). $(38,39)$ In the present study, the search for terms characterizing patient problems in their admission notes (chapter on 'relevant comorbidities' and 'active problems') was not sufficiently specific. The absence of intervention was mainly related to false-positive alerts (e.g., ruling out epilepsy or a history of alcohol withdrawal seizures was sufficient to trigger an alert in the presence of a drug lowering the patient's seizure threshold). We believe that these issues will be partially solved by the General Internal Medicine Department's recent deployment of a structured patient-problem list, the use of which has led to a clear decrease in free-text entries over the last three years on several wards. (40)

\section{Clinical context and physicians' awareness of risk situations}

Two clinical rules involving DDIs were the third reason for triggering an alert, with an intervention PPV of $28.2 \%$ (71 alerts led to 20 interventions). However, given the clinical context, it should be noted that only the clinical rule regarding the interaction of two anticoagulant drugs led to pharmaceutical interventions (intervention PPV $=52.6 \%$ ). In contrast, pharmacists never intervened for interactions between two serotoninergic drugs, with an increased risk of serotonin syndrome. It has been shown that integrating contextual information is a key factor in improving the PPV for medication alerts and particularly for DDI 
alerts. (29) Additionally, two of the most significant contextual factors that should help clinicians' decision-making within a CDSS are the 'severity of the effect' and the 'patient's clinical condition'; however, they remain difficult to consult using clinical rules based on explicit criteria (e.g., laboratory values, demographic data). Thus, contextual factors depend mainly on clinicians' judgment. (41) Clearly, the prescription of two anticoagulants should be avoided, given the 'severity of effect' of the pharmacodynamic interaction. Furthermore, all of these alerts were accompanied by an intervention except in situations involving the misuse of the CPOE (two anticoagulants prescribed simultaneously when they should be alternated and for which the temporal sequence was clearly indicated in the free-text section of the medication order aimed at the nurse). On the other hand, no interventions were carried out when two serotoninergic drugs were combined, since, in each case, the doses were low to medium, the patient's clinical context was incompatible with a serotoninergic syndrome, and the treatments were being taken on a long-term basis and were well tolerated. Similarly, considering the clinical context helps to explain the disparity between PPVs for alerts regarding a drug prescription combined with an abnormal laboratory value, indicating a potential overdosage or the risk of an adverse effect: in all the prescriptions for blood-glucose-lowering drugs associated with hypoglycemia, the situation was already being managed at the time of screening, and the PPV was zero. Physicians closely monitored heparin prescriptions in the presence of thrombopenia, as most of the patients concerned were still being monitored for hemopathy. Moreover, the likelihood of heparin-induced thrombocytopenia was very limited and the PPV was low. Finally, the intervention PPV was higher in the presence of hypokaliemia on digoxin, or hyperlactatemia on metformin, due to the severity of the adverse effects and an unfavorable benefitrisk ratio. $(42,43)$ PharmaCheck's development has taken into account the need to contextualize alerts using patient data (e.g., medication and dosage, previous laboratory values). Thus, a significant effort has been made to display useful patient data from their EHRs directly adjacent to alerts, thus increasing the screening tool's ergonomics. (44)

\section{Redundant safeguards}

Alerts associated with an inappropriate mode of administration were the least frequently triggered $(n=7)$ and had the lowest proportional intervention PPV (14.3\%). These clinical rules targeted drugs described in the list of 'never events' for which the occurrence of an ADE may lead to a life-threatening situation. (20) Thus, methotrexate and potassium chloride were already the targets of priority safety actions when PharmaCheck was deployed. Among the strategies that can be used to prevent a specific $A D E$, medication dosing support (providing common medication dosages) has been shown to be effective. $(45,46)$ However, deviations from prescriptions are still theoretically possible; for example, a prescription of two separate single doses of methotrexate at an interval of less than 7 days is possible despite a locked-in administration frequency option (once a week) and a duplicate alert trigger. PharmaCheck was also used to complete the arsenal of tools for preventing 'never events', even though their probability of occurrence is very low, as shown by the low intervention PPV (the only intervention concerned a severe hypokalemia, for which a potassium chloride infusion rate of $>10 \mathrm{mmol} /$ hour was prescribed without any documentation on cardiac monitoring). Similarly, a clinical rule concerning the 
prescription of vitamin $\mathrm{K}$ antagonists and supra-therapeutic INR (36 alerts) induced few interventions (intervention PPV $=19.40 \%$ ) thanks to the prescription security provided by corollary orders (INR are automatically ordered and displayed for each vitamin $\mathrm{K}$ antagonists prescription/dose adjustment). $(45,47)$

Studying PharmaCheck's performance in detecting high-risk situations led us to define the three characteristics of an 'ideal' alert-one that would be triggered for most relevant situations.

- The alert should be based on the selection of a trigger or set of triggers that best characterize a clinical situation (e.g., alerts concerning a drug prescription with renal failure should be based on the most relevant weight value between measured, adjusted, or ideal body-weight should also be triggered according to the evolution of renal function, taking into account previous measurements).

- The alert's content should facilitate clinical contextualization by highlighting the risk factors likely to trigger an intervention or, on the contrary, protective factors unlikely to trigger an intervention (e.g., displaying the list of prescribed CYP3A4-inhibiting drugs that constitute an additional risk factor for the accumulation of direct oral anticoagulants and an acute renal failure alert; displaying any prescription for potassium supplementation indicating the management of hypokaliemia when the alert for the contraindication of digoxin for hypokaliemia is activated).

- Alerts should be displayed in an order that allows priority treatment for the riskiest situations (e.g., considering the patient's age or whether an alert is already redundant).

\section{PharmaCheck's impact on the activity of clinical pharmacists}

\section{PharmaCheck's integration into daily clinical pharmacy routines}

A total of 447 alerts were triggered, and PharmaCheck produced between 3 and 4 new alerts per day. Concerning workloads, the time required to process alerts was not accurately measured (estimated at 1 to 3 hours per day, including reviewing new alerts and repetitive alerts occurring during several rounds of PharmaCheck use). Users nevertheless agreed on the need to allocate more time for analysis when alerts are first triggered (compared to an alert that has already been analyzed and requires a simple follow-up). Using PharmaCheck daily seemed to be a reasonable use of time-a means to avoid missing any important warnings resulting from new or changed prescriptions and potentially leading to an ADE. One study has estimated that using a monitoring system involving a pharmacist requires 1.5 hours per day (working with 3.6 alerts/day). In addition, those authors calculated that when alerts could not be analyzed daily, $36 \%$ of the notified situations handled retroactively (after 24 hours) were associated with an ADE. (30) This suggests that screening would be most effective as part of daily routines. 


\section{PharmaCheck's addition to traditional on-ward clinical pharmacy activities}

Fifteen of the 20 clinical rules led to an intervention, with a final clinical PPV of $71 \%$ when alerts were filtered by a clinical pharmacist. This rate is close to those observed when using similar screening tools dedicated to pharmacists (63\% to $83 \%$ for 300 to 554 interventions). (31-33) PharmaCheck was based on a back-office approach complementing standard clinical pharmacy activities (medication review during medical rounds), and the majority of interventions were carried out by telephone (as only a minority of situations involved patients admitted to a ward covered by a clinical pharmacist). A previous study in our participating General Internal Medicine ward showed a slightly higher final clinical PPV, around $80 \%$. (19) In contrast, several studies have shown that acceptance rates for pharmacists' interventions were significantly lower for back-office or written interventions than for on-ward or verbal advice or interventions. $(19,48)$ A pharmacist's presence on a ward is more conducive to interventions as visibility and recognition are better and timing has a greater impact. There is also better contextualization because the information used is captured during pharmacists' visits. (49) Indeed, combining an on-ward approach with back-office screening and interventions for high-risk situations is an efficient and acceptably safe way to expand a clinical pharmacist's coverage (and workload): in addition to 2-5 weekly typical on-ward visits covering 15-45 inpatients, PharmaCheck back-office use makes it possible to monitor 20 high-risk situations for approximately 200 additional patients every day.

The main reason (85.2\%) why physicians did not follow therapeutic adjustment proposals was a positive benefit-risk ratio. Although the risks associated with situations were explained during telephone calls with physicians, it was not always easy to weigh up the benefits from a distance, without being present on the ward, and without an initial discussion with the patient's care team.

\section{PharmaCheck's use in addition to CDSS for physicians}

We used the final clinical PPV without a pharmacist's intervention as a proxy measure of the impact PharmaCheck would have had if used as a standalone tool dedicated to physicians. Under these circumstances, a maximum of $14 \%$ of alerts would have been associated with a change in prescription. It is noteworthy that our approach assumes that every risk situation that led to a pharmaceutical intervention and a prescription modification would have been recognized as relevant by physicians and would have led to the same modifications. This optimistic assumption is consistent with results showing that using a CDSS for prescribing medication has a statistically significant positive effect on a physician's practice performance. $(50,51)$ The main benefits of using a CDSS were better quality prescriptions and lower rates of medication errors. Becke and al. supported this finding: they measured acceptance rates (i.e., prescription modification) varying between $14.0 \%$ and $90.0 \%$ for five alerts appearing as pop-ups on physicians' digital interfaces during order entry. (52) Thus, one prospect for this system could be to adapt some of the PharmaCheck alerts to notify physicians as they are prescribing, particularly for those alerts whose final clinical PPVs with and without a pharmacist are similar. Finally, 
the only clinical rule fulfilling this criterion was digoxin combining a supra-therapeutic digoxinemia rate. For the other rules, the final clinical PPVs with a pharmacist were 1.3 to 67 times higher than without one. Thus, a large proportion of alerts would be deemed irrelevant and adherence to PharmaCheck would be compromised given the risk of alert fatigue if alerts were addressed exclusively to physicians. (36) Nevertheless, it should be noted that the clinical rules actively triggered when a caregiver consults the patient's record at the time of prescription do not consider that the situation might evolve during hospitalization and require subsequent adjustment (before the patient file is consulted again). CDSSs like PharmaCheck enable continuous passive monitoring. Thus, the prescription of a direct oral anticoagulant initiated several days before, associated with a sudden and brutal deterioration of renal function, will trigger an alert as soon as the laboratory results are published.

\section{Limitations}

One of our study's main limitations is the large number of alerts that were deemed irrelevant and for which no intervention was made (about $80 \%$ of alerts). As already discussed, one of the main reasons for this over-representation is related to the quality of the data related to patients' problems (the second most common risk category) and the insufficient specificity of some clinical rules. The recent reconfiguration of the clinical rules in our EHR to take into account these structural problems will certainly solve some of them. (52) Moreover, PharmaCheck's specificity could be improved by adjusting queries to consider several discriminating conditions, such as the addition of temporal and dynamic aspects (e.g., a sudden drop in renal function).

Another limitation is that the potential negative predictive values of the different clinical rules have not been assessed, as this would have created a heavy workload and required a manual chart review. However, except for patient problems, the triggers for PharmaCheck's alerts are structured data (ATC codes, dosage values, biological analysis identifiers, etc.) that have been previously listed for query creation. Thus, these data are in our system permanently and we expect a low proportion of falsenegative alerts.

PharmaCheck can identify high-risk situations at a distance from the prescriber, but it may take several hours each days for the pharmacist to check for alerts (PharmaCheck runs at a fixed time on weekdays), meaning the occurrence of adverse events remains possible. Indeed, PharmaCheck complements a system currently being deployed that is based on alerts sent to physicians as they are prescribing drugs. $(53,54)$ An overall strategy will thus make it possible to consolidate prescription safety by combining multiple contextualized alerts, monitoring opportunities, and targeted healthcare professionals.

\section{Conclusions}

With a relatively small investment in human resources, using PharmaCheck enables clinical pharmacists to expand their reach in screening for several high-risk situations for every patient admitted to our General Internal Medicine Department. This tool, therefore, boosts the efficiency of our clinical pharmacists and 
improves patient safety. Our study underlined the importance of professionalizing the management of alerts generated by a clinical decision support system and filtered by a pharmacist. This approach enabled the selection of the most relevant alerts to send to physicians and led to changes in prescriptions in most cases. Without filtering by a pharmacist, physicians would have had to identify the minority of relevant situations in a large number of alerts, a circumstance that runs the risk of creating alert fatigue and poor adherence to the system. The adoption of PharmaCheck by other departments (e.g., geriatrics, oncology, pediatrics) will involve the system being adapted to other specific populations for whom situations at a high- risk of adverse drug events must be characterized.

\section{Abbreviations}

ADEs: adverse drug events

AF: atrial fibrillation

ATC: anatomical therapeutic chemical

CDSS: a clinical decision support system

CG: Cockcroft-Gault

CKD-EPI: Chronic Kidney Disease Epidemiology Collaboration

CICG: estimated creatinine clearance using the Cockcroft-Gault formula

CPOE: computerized physician order entry

CYP3A4: Cytochrome P450 3A4

DDI: drug-drug interaction

DOAC: direct oral anticoagulant

eGFR: estimated glomerular filtration rate

EHR: electronic health records

INR: international normalized ratio

IQR: interquartile range

LMWH: low molecular weight heparin

MTX: methotrexate

NSAID: non-steroidal anti-inflammatory drug 
P-gp: permeability glycoprotein

PPV: positive predictive value

PRN: as needed

SD: standard deviation

UFH: unfractionated heparin

VKA: vitamin $\mathrm{K}$ antagonist

VTE: venous thromboembolism

\section{Declarations}

\section{Ethics approved and consent to participate}

The waiver of informed consent was reviewed and approved by the Ethics Committee of the Canton of Geneva (Req-2019-01266) as this quality-improvement study was set up as standard practice not falling within the scope of the Swiss law on research on human beings (the project was part of quality improvement of care process without the objective of being a scientific research on human diseases or on the structure and functioning of the human body). All experiments were performed in accordance with relevant guidelines and regulations.

\section{Consent for publication}

Not applicable.

\section{Availability of data and materials}

The datasets used and/or analysed during the current study are available from the corresponding author on reasonable request.

\section{Competing interests}

All authors declare that they have no competing interests.

\section{Funding}

The study was not funded. 


\section{Authors' contributions}

CS developed the CDSS with the technical support of FE, DG and DT. CS, BG, PB designed the study and performed analysis, writing and revision of the manuscript. CS, BG, MJ and CB implemented the study. PB and BG did supervision and JLR, OG and JS reviewed the manuscript. All authors approved their submission for publication.

\section{Acknowledgement}

We thank the clinical pharmacy team at the Valais Hospital-particularly Johnny Beney, Vera Joran-von Gunten, Anne-Valérie Luyet, and Laurie Bochatay-for their availability, sharing their experiences with their CDSS dedicated to clinical pharmacists, and for the content of their clinical rules and decision-making algorithms

\section{References}

1. Expert Group on Safe Medication. Glossary of terms related to patient and medication safety Committee of Experts on Management of Safety and Quality in Health Care [Internet]. 2005 [cité 6 mai 2021]. Disponible sur: https://www.who.int/patientsafety/highlights/COE_patient_and_medication_safety_gl.pdf

2. Cano FG, Rozenfeld S. Adverse drug events in hospitals: a systematic review. Cad Saude Publica. 2009;25 Suppl 3:S360-372.

3. Batel Marques F, Penedones A, Mendes D, Alves C. A systematic review of observational studies evaluating costs of adverse drug reactions. Clinicoecon Outcomes Res. 24 août 2016;8:413-26.

4. Leape LL, Brennan TA, Laird N, Lawthers AG, Localio AR, Barnes BA, et al. The nature of adverse events in hospitalized patients. Results of the Harvard Medical Practice Study II. N Engl J Med. 7 févr 1991;324(6):377-84.

5. Medication Errors and Adverse Drug Events. [cité 6 mai 2021]; Disponible sur: https://psnet.ahrq.gov/primer/medication-errors-and-adverse-drug-events

6. Wolfe D, Yazdi F, Kanji S, Burry L, Beck A, Butler C, et al. Incidence, causes, and consequences of preventable adverse drug reactions occurring in inpatients: A systematic review of systematic reviews. PLoS One [Internet]. 11 oct 2018 [cité 6 mai 2021];13(10). Disponible sur: https://www.ncbi.nlm.nih.gov/pmc/articles/PMC6181371/

7. Preventing Medication Errors: Quality Chasm Series. [cité 6 mai 2021]; Disponible sur: https://psnet.ahrq.gov/issue/preventing-medication-errors-quality-chasm-series

8. Agrawal A. Medication errors: prevention using information technology systems. Br J Clin Pharmacol. juin 2009;67(6):681-6. 
9. Khanna R, Yen T. Computerized Physician Order Entry. Neurohospitalist. janv 2014;4(1):26-33.

10. Beeler PE, Bates DW, Hug BL. Clinical decision support systems. Swiss Medical Weekly [Internet]. 15 déc 2014 [cité 6 mai 2021];144(5152). Disponible sur: https://smw.ch/article/doi/smw.2014.14073

11. Slight SP, Nanji KC, Seger DL, Cho I, Volk LA, Bates DW. Overrides of clinical decision support alerts in primary care clinics. Stud Health Technol Inform. 2013;192:923.

12. Hammar T, Lidström B, Petersson G, Gustafson Y, Eiermann B. Potential drug-related problems detected by electronic expert support system: physicians' views on clinical relevance. Int J Clin Pharm. 1 oct 2015;37(5):941-8.

13. Weingart SN, Simchowitz B, Padolsky H, Isaac T, Seger AC, Massagli M, et al. An empirical model to estimate the potential impact of medication safety alerts on patient safety, health care utilization, and cost in ambulatory care. Arch Intern Med. 14 sept 2009;169(16):1465-73.

14. Ancker JS, Edwards A, Nosal S, Hauser D, Mauer E, Kaushal R. Effects of workload, work complexity, and repeated alerts on alert fatigue in a clinical decision support system. BMC Med Inform Decis Mak [Internet]. 10 avr 2017 [cité 7 mai 2021];17. Disponible sur: https://www.ncbi.nlm.nih.gov/pmc/articles/PMC5387195/

15. Kaboli PJ, Hoth AB, McClimon BJ, Schnipper JL. Clinical pharmacists and inpatient medical care: a systematic review. Arch Intern Med. 8 mai 2006;166(9):955-64.

16. Rotta I, Salgado TM, Silva ML, Correr CJ, Fernandez-Llimos F. Effectiveness of clinical pharmacy services: an overview of systematic reviews (2000-2010). Int J Clin Pharm. oct 2015;37(5):687-97.

17. Frontini R, Miharija-Gala T, Sykora J. EAHP survey 2010 on hospital pharmacy in Europe: parts 4 and 5. Clinical services and patient safety. European Journal of Hospital Pharmacy: Science and Practice. 1 avr 2013;20(2):69-73.

18. Messerli M, Maes KA, Hersberger KE, Lampert ML. Mapping clinical pharmacy practice in Swiss hospitals: a cross-sectional study. Eur J Hosp Pharm. 26 févr 2016;ejhpharm-2015-000868.

19. Guignard B, Bonnabry P, Perrier A, Dayer P, Desmeules J, Samer CF. Drug-related problems identification in general internal medicine: The impact and role of the clinical pharmacist and pharmacologist. Eur J Intern Med. juill 2015;26(6):399-406.

20. NHS England » Never events [Internet]. [cité 7 janv 2021]. Disponible sur: https://www.england.nhs.uk/publication/never-events/

21. Institute for safe Medication Practices. ISMP's List of High-Alert Medications [Internet]. ISMP; Disponible sur: http://www.ismp.org/tools

22. Luyet A-V, Gunten VJ, Turini P, Beney J. NP-011 Mediscreen: implementation of a tool for detecting patients at risk of adverse drug events via the electronic medical record. Eur J Hosp Pharm. 1 mars 2019;26(Suppl 1):A295-A295.

23. The most popular database for modern apps [Internet]. MongoDB. [cité 7 janv 2021]. Disponible sur: https://www.mongodb.com/3 
24. The Professional Client, IDE \& GUI for MongoDB [Internet]. Studio 3T. [cité 7 janv 2021]. Disponible sur: https://studio3t.com/

25. Berner ES, La Lande TJ. Overview of Clinical Decision Support Systems. In: Berner ES, éditeur. Clinical Decision Support Systems: Theory and Practice [Internet]. Cham: Springer International Publishing; 2016 [cité 15 avr 2021]. p. 1-17. (Health Informatics). Disponible sur: https://doi.org/10.1007/978-3319-31913-1_1

26. Lavan AH, Gallagher P. Predicting risk of adverse drug reactions in older adults. Ther Adv Drug Saf. févr 2016;7(1):11-22.

27. Urbina O, Ferrández O, Grau S, Luque S, Mojal S, Marin-Casino M, et al. Design of a score to identify hospitalized patients at risk of drug-related problems. Pharmacoepidemiol Drug Saf. sept 2014;23(9):923-32.

28. Montamat SC, Cusack BJ, Vestal RE. Management of drug therapy in the elderly. N Engl J Med. 3 août 1989;321(5):303-9.

29. Carli D, Fahrni G, Bonnabry P, Lovis C. Quality of Decision Support in Computerized Provider Order Entry: Systematic Literature Review. JMIR Medical Informatics. 24 janv 2018;6(1):e7170.

30. Jha AK, Laguette J, Seger A, Bates DW. Can Surveillance Systems Identify and Avert Adverse Drug Events? A Prospective Evaluation of a Commercial Application. J Am Med Inform Assoc. 2008;15(5):647-53.

31. Quintens C, De Rijdt T, Van Nieuwenhuyse T, Simoens S, Peetermans WE, Van den Bosch B, et al. V: Development and implementation of « Check of Medication Appropriateness » (CMA): advanced pharmacotherapy-related clinical rules to support medication surveillance. BMC Med Inform Decis Mak. 11 2019;19(1):29.

32. Rommers MK, Zwaveling J, Guchelaar H-J, Teepe-Twiss IM. Evaluation of rule effectiveness and positive predictive value of clinical rules in a Dutch clinical decision support system in daily hospital pharmacy practice. Artificial Intelligence in Medicine. 1 sept 2013;59(1):15-21.

33. Ibáñez-Garcia S, Rodriguez-Gonzalez C, Escudero-Vilaplana V, Martin-Barbero ML, Marzal-Alfaro B, De la Rosa-Triviño JL, et al. Development and Evaluation of a Clinical Decision Support System to Improve Medication Safety. Appl Clin Inform. mai 2019;10(3):513-20.

34. Wilhelm SM, Kale-Pradhan PB. Estimating creatinine clearance: a meta-analysis. Pharmacotherapy. juill 2011;31(7):658-64.

35. Bouquegneau A, Vidal-Petiot E, Moranne O, Mariat C, Boffa J, Vrtovsnik F, et al. Creatinine-based equations for the adjustment of drug dosage in an obese population. Br J Clin Pharmacol. févr 2016;81(2):349-61.

36. Sutton RT, Pincock D, Baumgart DC, Sadowski DC, Fedorak RN, Kroeker KI. An overview of clinical decision support systems: benefits, risks, and strategies for success. npj Digital Medicine. 6 févr 2020;3(1):1-10.

37. Electronic Health Record Problem Lists: Accurate Enough for Risk Adjustment? [Internet]. AJMC. [cité 16 avr 2021]. Disponible sur: https://www.ajmc.com/view/electronic-health-record-problem-lists- 
accurate-enough-for-risk-adjustment

38. Wilshire CL, Fuller CC, Gilbert CR, Handy JR, Costas KE, Louie BE, et al. Electronic Medical Record Inaccuracies: Multicenter Analysis of Challenges with Modified Lung Cancer Screening Criteria. Canadian Respiratory Journal. 26 mars 2020;2020:e7142568.

39. Kane-Gill SL, MacLasco AM, Saul MI, Smith TRP, Kloet MA, Kim C, et al. Use of Text Searching for Trigger Words in Medical Records to Identify Adverse Drug Reactions within an Intensive Care Unit Discharge Summary. Appl Clin Inform. 17 juill 2016;7(3):660-71.

40. One list to rule them all and many semantics to bind them: Building a shared, scalable and sustainable source for the problem oriented medical record [Internet]. JMIR Preprints. [cité 18 avr 2021]. Disponible sur: https://preprints.jmir.org/preprint/29174

41. Wasylewicz ATM, Scheepers-Hoeks AMJW. Clinical Decision Support Systems. In: Kubben P, Dumontier M, Dekker A, éditeurs. Fundamentals of Clinical Data Science [Internet]. Cham (CH): Springer; 2019 [cité 22 avr 2021]. Disponible sur: http://www.ncbi.nlm.nih.gov/books/NBK543516/

42. DeFronzo R, Fleming GA, Chen K, Bicsak TA. Metformin-associated lactic acidosis: Current perspectives on causes and risk. Metabolism. 1 févr 2016;65(2):20-9.

43. Mladěnka P, Applová L, Patočka J, Costa VM, Remiao F, Pourová J, et al. Comprehensive review of cardiovascular toxicity of drugs and related agents. Med Res Rev. juill 2018;38(4):1332-403.

44. Miller K, Mosby D, Capan M, Kowalski R, Ratwani R, Noaiseh Y, et al. Interface, information, interaction: a narrative review of design and functional requirements for clinical decision support. $J$ Am Med Inform Assoc. 6 nov 2017;25(5):585-92.

45. Wright A, Sittig DF, Ash JS, Feblowitz J, Meltzer S, McMullen C, et al. Development and evaluation of a comprehensive clinical decision support taxonomy: comparison of front-end tools in commercial and internally developed electronic health record systems. J Am Med Inform Assoc. 2011;18(3):23242.

46. Lee J, Han H, Ock M, Lee S, Lee S, Jo M-W. Impact of a clinical decision support system for high-alert medications on the prevention of prescription errors. International Journal of Medical Informatics. 1 déc 2014;83(12):929-40.

47. Netgen. Introduction de l'acénocoumarol à l'aide d'un algorithme de prescription [Internet]. Revue Médicale Suisse. [cité 22 avr 2021]. Disponible sur: https://www.revmed.ch/RMS/2010/RMS235/Introduction-de-l-acenocoumarol-a-l-aide-d-un-algorithme-de-prescription

48. Lagreula J, Maes F, Wouters D, Quennery S, Dalleur O. Optimizing pharmacists' detection of prescribing errors: Comparison of on-ward and central pharmacy services. Journal of Clinical Pharmacy and Therapeutics [Internet]. [cité 23 avr 2021];n/a(n/a). Disponible sur: https://onlinelibrary.wiley.com/doi/abs/10.1111/jcpt.13339

49. Bedouch P, Tessier A, Baudrant M, Labarere J, Foroni L, Calop J, et al. Computerized physician order entry system combined with on-ward pharmacist: analysis of pharmacists' interventions. Journal of Evaluation in Clinical Practice. 2012;18(4):911-8. 
50. Taheri Moghadam S, Sadoughi F, Velayati F, Ehsanzadeh SJ, Poursharif S. The effects of clinical decision support system for prescribing medication on patient outcomes and physician practice performance: a systematic review and meta-analysis. BMC Medical Informatics and Decision Making. 10 mars 2021;21(1):98.

51. Reis WC, Bonetti AF, Bottacin WE, Reis AS, Souza TT, Pontarolo R, et al. Impact on process results of clinical decision support systems (CDSSs) applied to medication use: overview of systematic reviews. Pharm Pract (Granada) [Internet]. 2017 [cité 29 avr 2021];15(4). Disponible sur: https://www.ncbi.nlm.nih.gov/pmc/articles/PMC5741996/

52. Becker ML, Baypinar F, Pereboom M, Lilih S, van der Hoeven RTM, Giezen TJ, et al. The effect of medication related clinical decision support at the time of physician order entry. Int J Clin Pharm. 1 févr 2021;43(1):137-43.

53. Home - MedBase [Internet]. [cité 29 avr 2021]. Disponible sur: https://www.medbase.fi/en/

54. Médicaments: être vigilant mais à bon escient! [Internet]. Fondation privée des HUG. [cité 29 avr 2021]. Disponible sur: https://www.fondationhug.org/Medicaments_vigilance

55. Huibers CJA, Sallevelt BTGM, de Groot DA, Boer MJ, van Campen JPCM, Davids CJ, et al. Conversion of STOPP/START version 2 into coded algorithms for software implementation: A multidisciplinary consensus procedure. International Journal of Medical Informatics. 1 mai 2019;125:110-7.

56. Desnoyer A, Blanc A-L, Pourcher V, Besson M, Fonzo-Christe CC, Desmeules JA, et al. PIM-Check: development of an international prescription-screening checklist designed by a Delphi method for internal medicine patients. BMJ Open. 2017;7(7):e016070.

57. La revue Pharma-Flash du service de pharmacologie et toxicologie clinique à Genève aux HUG [Internet]. [cité 8 janv 2021]. Disponible sur: https://www.hug.ch/pharmacologie-toxicologiecliniques/pharma-flash

\section{Table}

Due to technical limitations, table 3 is only available as a download in the Supplemental Files section.

\section{Figures}




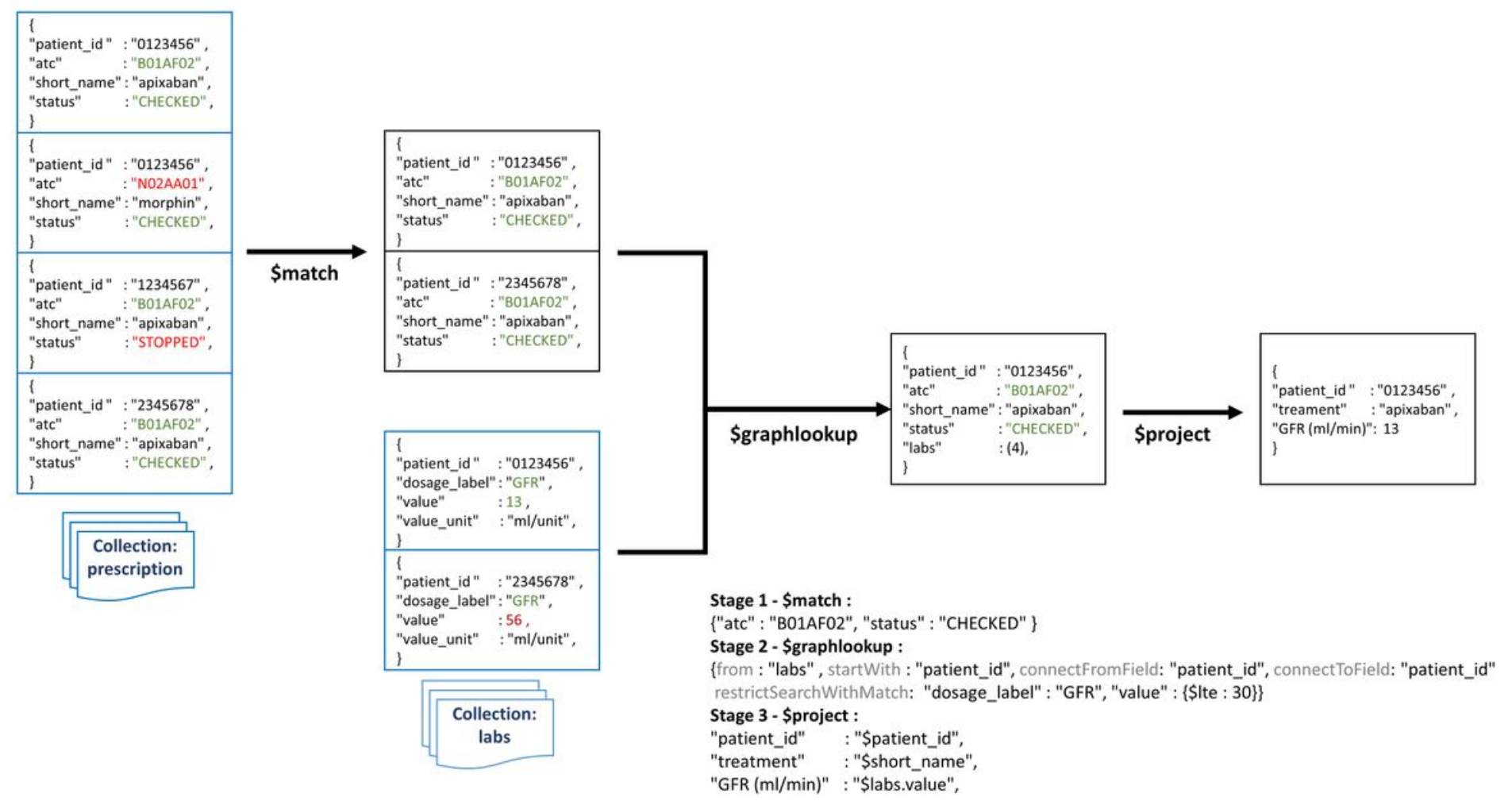

\section{Figure 1}

Example of an aggregation pipeline (prescription of a direct oral anticoagulant in the presence of acute renal failure) This three-stages aggregation query describes how EHR are filtered to identify patients with at least one apixaban prescription and an estimated glomerular renal function (GFR) lower than $30 \mathrm{~mL} / \mathrm{min}$ : First Stage: The \$match stage filters the prescription database to identify the medication by its anatomical therapeutic chemical (atc) code and its status. Only prescriptions that concern apixaban (atc equal to "B01AF02") and that have be signed and are still active (status equal to "CHECKED") pass on to the next stage. Second Stage: The $\$$ graphlookup stage lookups laboratory values with a publication date of less than 30 days (step not shown in the example) for the patients identified with the first stage. Thus, lookup stage is performed in the list of all recent published laboratory data concerning patient(s) whose identifier ("patient_id") has been isolated in the first step and restricted to analysis with a dosage_label equal to "GFR" and a value lower than or equal to $30(\mathrm{~mL} / \mathrm{min})$. Third stage: The \$project stage enables the construction of the table of aggregated results with patient identifier (patient_id), medical order description (treatment), and eGFR value (GFR ( $\mathrm{ml} / \mathrm{min})$ ) 


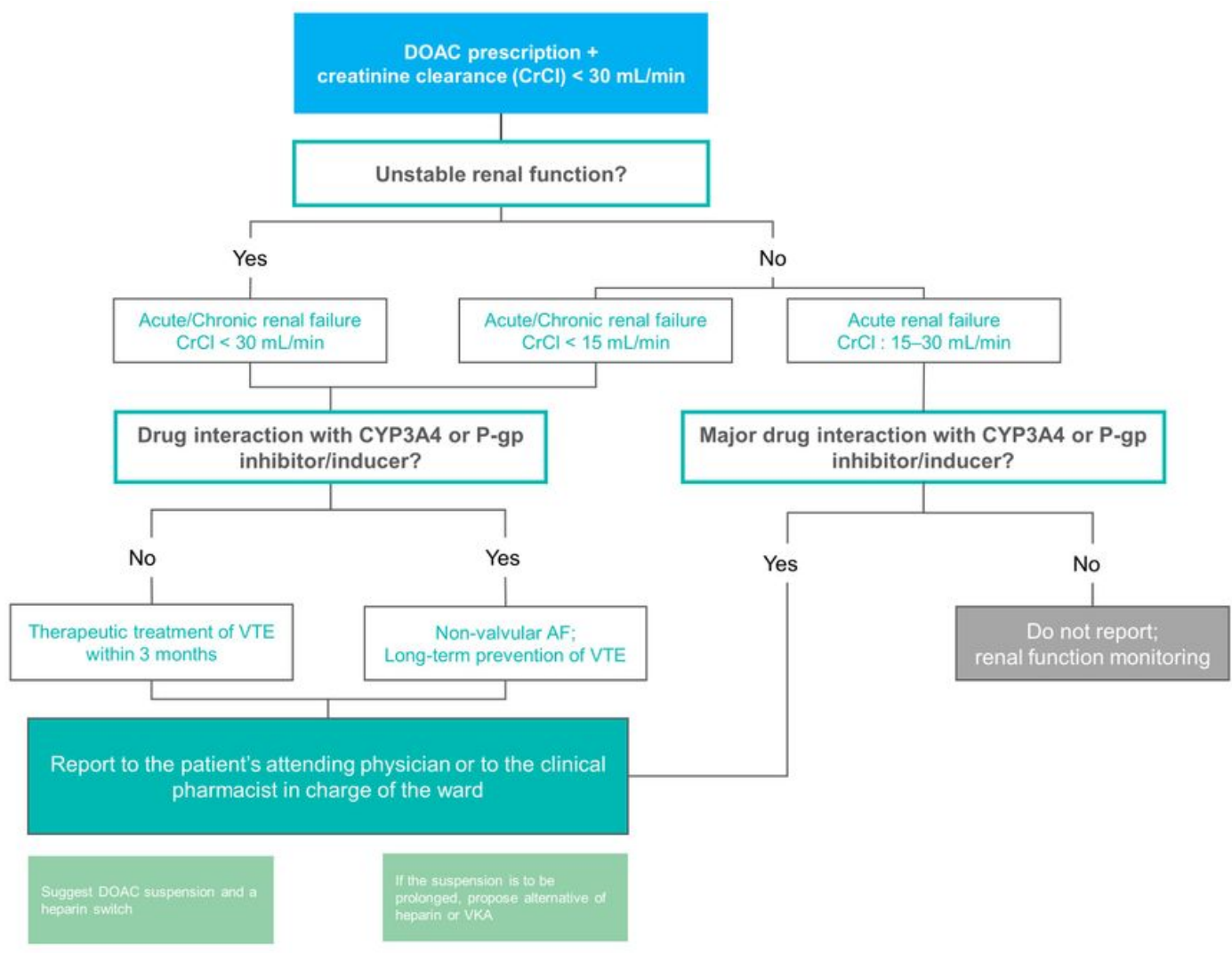

Figure 2

Example of a decisional algorithm (Direct oral anticoagulant prescription with renal failure) List of abbreviations: AF - atrial fibrillation; CYP3A4 - cytochrome P450 3A4; DOAC - direct anticoagulant oral therapy; P-gp - permeability glycoprotein ; VTE - venous thromboembolism; VKA - vitamin K antagonist.

\section{Supplementary Files}

This is a list of supplementary files associated with this preprint. Click to download.

- Table3.pptx 